DOI: 10.12731/2070-7568-2020-3-142-157

УДК 339.371

\title{
ПАРАЗИТИРОВАНИЕ В ИНТЕРНЕТ-КОММЕРЦИИ: ЭМПИРИЧЕСКИЙ АНАЛИЗ
}

\author{
Митяшин Г.Ю., Катрашова Ю.В.
}

В статье рассмотрен феномен паразитирования, представляющий собой покупку потребителем товара, после проверки его потребительских качеств в традиционном магазине. Описаны разновидности данного феномена: межфирменное и внутрифирменное паразитирование. Для получения более детальной информации о феномене паразитирования в интернет-коммерции авторами был проведен опрос, наглядно демонстрирующий поведение потребителей при покупке товаров в интернете. В заключении сформулированы рекомендации, позволяюшие минимизировать негативное влияние данного феномена.

Цель исследования: выявить существование феномена паразитирования в интернет-коммерциии и предложить возможные варианты борьбы с ним.

Метод или методология проведения работы: метод анкетирования, метод формализации, метод анализа и синтеза, метод описания.

Результаты: обосновано существование феномена паразитирования в интернет-коммерциии и сформулированы рекомендации, позволяюшие снизить его негативный эффект.

Область применения результатов: полученные результаты ичелесообразно применять управляющим розничными торговыми предприятиями для повышения эффективности их деятельности путем минимизации негативного влияния феномена паразитирования в интернет-коммеричии.

Ключевые слова: интернет-магазин; традиционный магазин; торговля; интегрированный канал сбыта; паразитирование; поведение потребителей; Интернет-торговля. 


\section{PARASITISM IN E-COMMERCE: EMPIRICAL ANALYSIS}

\section{Mityashin G.Yu., Katrashova Yu.V.}

The article deals with the phenomenon of parasitism, which is a consumer's purchase of a product after checking its consumer qualities in a traditional store. This phenomenon has two types: inter-company and intra-company parasitism. To get more detailed information about the phenomenon of parasitism e-commerce, the authors conducted an interview that clearly demonstrates the behavior of consumers when buying goods on the Internet. Recommendations which help to minimize the negative impact of this phenomenon were formulated in conclusion.

Purpose: identify the existence of the phenomenon of parasitism in e-commerce and suggest possible ways to reject it.

Methodology: the questioning method, the method of formalization, analysis and synthesis, method of description.

Results: the existence of the phenomenon of parasitism in e-commerce is substantiated and recommendations to reduce its negative effect were formulated.

Practical implications: the obtained results should be used by managers of retail enterprises to improve their efficiency by minimizing the negative impact of the phenomenon of parasitism in e-commerce.

Keywords: online store; traditional store; trade; integrated sales channel; parasitism; consumer behavior; e-commerce.

\section{Введение}

Интернет-коммерция стала важной инновацией в торговой деятельности, сущность, роль и значение которой получила широкое освещение в современной научной литературе $[1,4,5,7,912,13$, $14,16]$. Данный вид торговли имеет свои отличительные особенности: более низкая цена относительно традиционного магазина, возможность приобрести товар из любого места и в любое время, невозможность самостоятельно ознакомиться с выбранным товаром $[2,6,10]$. 
Из-за появления такого формата торговли у потребителя появляется возможность выбора между традиционным магазином и интернет-магазином [11]. Клиент, зная преимущества и недостатки каждого из обозначенных форматов, старается избрать такую модель поведения, которая позволяет максимизировать выгоду (приобрести товар по более низкой цене) и минимизировать риски, которые образуются в виду невозможности проверить качество и потребительские свойства товара при оформлении заказа через интернет. Таким образом, потребитель может действовать двумя способами:

1. Выбрать товар в интернете, а затем проверить его потребительские свойства в традиционном магазине (и в случае, если покупатель удовлетворен, приобрести его в интернете).

2. Найти необходимый товар в традиционном магазине, а затем купить его через интернет $[8,15]$.

Данные модели поведения можно назвать паразитированием [8]. Его суть заключается в естественном стремлении потребителя получить максимальную выгоду при минимальном вложении денег. В данном случае традиционный магазин, который предлагает возможность ознакомиться с товаром и приобрести его незамедлительно, но по более высокой цене, является менее привлекательным, чем интернет-магазин, который предлагает аналогичный товар дешевле [7]. Именно поэтому покупатель в итоге выбирает покупку через интернет, полностью получив необходимую информацию о товаре в традиционном магазине, что снижает эффективность деятельности последнего. В этом случае потребитель безвозмездно использует ресурсы традиционного магазина для минимизации своих издержек и рисков. Отметим, что описанная модель поведения характерна не для всех групп населения и не для всех категорий товаров. Вероятно, данная схема используется людьми с невысоким доходом (стремятся снизить затраты), бережливыми и требовательными людьми (не станут приобретать товар, пока не убедятся в его качестве) или при покупках на крупную сумму (хотят убедиться в качестве товаров, но получить его с доставкой на дом). Данная модель поведения также нехарактерна для пожилых людей, которые не владеют 
электронным девайсами на уровне, позволяющем сделать заказ через интернет. По такой схеме приобретаются, как правило, высоко стандартизированные товары длительного пользования (например, бытовая техника, товары для дома, книги) [8, 15].

На традиционном магазине паразитирует не клиент, а интернетмагазин, который, не вкладывая средства в помещение для ознакомления с товаром и в штат продавцов, получает косвенную выгоду от функционирования традиционного магазина [8].

Отметим, что феномен паразитирования не стоит воспринимать как конкуренцию, потому что в данном случае речь идет об использовании ресурсов соперника (в случае внутрифирменного паразитирования соперником является другое структурное подразделение компании) для повышения собственной эффективности. Также отметим, что паразитирование зачастую не является результатом целенаправленной деятельности интернет-магазина. Оно обусловлено желанием покупателя получить максимальную выгоду и минимизировать риски при осуществлении покупки через интернет-магазин.

Цели исследования: выявление закономерностей паразитирования в интернет-коммерции.

Методы и материалы: в работе применялся общенаучный методы анализа и синтеза. Для выявления особенностей поведения потребителей нами был проведен опрос.

В начале работы нами было выдвинуто предположение, что описываемая модель поведения характерна для людей, имеющих возможность осуществлять покупки через интернет, но не обладающих высоким доходом. Поэтому для анкетирования было выбрано 19 респондентов в возрасте 18-22 лет, которые являются студентами, следовательно, хорошо владеют гаджетами и стремятся получать максимальную выгоду от покупок в силу ограниченности бюджета.

Основные результаты исследования. Паразитирование в интернет коммерции в зависимости от формы может быть внутрифирменным и межфирменным $[8,15]$.

При внутрифирменном паразитировании клиент после посещения традиционного магазина совершает покупку в интернет магази- 
не той же компании. Зачастую покупка в интернет-магазине совершается незамедлительно после консультации, так как у большинства покупателей, которые придерживаются описываемой модели поведения, есть доступ в интернет и, соответственно, возможность оформить заказ сразу. Данное решение является оптимальным для покупателя, так как он одновременно использует преимущества обоих магазинов (ознакомление с товаром в традиционном и покупка по более низкой цене через интернет) и избавляется от недостатков (более высокая цена в традиционном магазине и время ожидания при покупке через интернет).

Может показаться, что для компании это все равно выгодно, ведь она в итоге продала товар клиенту, однако это не так. При формировании цены в традиционном магазине, в стоимость закладываются расходы на аренду площади и на работу квалифицированного персонала, который может предоставить полную информацию о товаре. Клиент приходит в магазин, но использует его исключительно как шоу-рум, а затем приобретает товар в интернет-магазине по более низкой цене. То есть он не оплачивает работу персонала и арендную плату, что снижает рентабельность не только традиционного магазина, но и всей компании в целом, так как нет уверенности в том, что прирост продаж в интернет магазине сможет компенсировать снижение дохода от традиционного магазина $[8,15]$.

Межфирменное паразитирование представляет собой ситуацию, когда клиент, посетив традиционный магазин (не имеющий собственного интернет-магазина) и получив необходимую информацию о товаре, совершает покупку через интернет-магазин другой компании. В такой ситуации традиционный магазин, выполнивший роль шоу-рума, не получает даже косвенного эффекта от взаимодействия с посетителем. Решить данную проблему можно либо создав собственный интернет магазин, что повлечет значительные затраты, либо путем выстраивания партнерских отношений со сторонним интернет-магазином, что потребует полной смены бизнес стратегии $[8,15]$.

Паразитирование в интернет-коммерции как экономический и маркетинговый феномен было выявлено и подробно описано в ра- 
боте [8]. Однако исследование [8] является скорее теоретическим. В нашей статье мы проведем эмпирический анализ феномена паразитирования.

100\% опрошенных используют интернет для совершения покупок, а 42\% делают это регулярно. Данный факт свидетельствует о том, что использование интернета для совершения покупок - обыденная практика для выбранной целевой аудитории.

В таблице 1 представлены ответы респондентов на вопрос: 'Какие товары Вы покупаете через интернет?”. Таблица показывает, что товары, наиболее часто приобретаемые через интернет, относятся к непродовольственной группе и имеют высокий уровень стандартизации. Интересно отметить, что порядка 20\% опрошенных совершают все покупки исключительно через интернет. Это говорит о полной готовности молодого поколения к осуществлению покупок исключительно в электронном формате, без использования традиционного магазина в качестве шоу-рума и, тем более, как места расчетов.

Таблицуа 1.

Товары, приобретаемые через интернет

\begin{tabular}{|c|c|c|c|}
\hline $\begin{array}{c}\text { № } \\
\text { п.п. }\end{array}$ & $\begin{array}{c}\text { Наименование } \\
\text { товарной группы }\end{array}$ & $\begin{array}{c}\text { Количество респондентов, } \\
\text { приобретающих данные } \\
\text { товары }\end{array}$ & $\begin{array}{c}\text { Доля респондентов, } \\
\text { приобретающих } \\
\text { данные товары }\end{array}$ \\
\hline 1 & Бытовая техника & 5 & $26 \%$ \\
\hline 2 & Книги & 2 & $11 \%$ \\
\hline 3 & Одежда & 4 & $21 \%$ \\
\hline 4 & Косметика & 3 & $16 \%$ \\
\hline 5 & Автозапчасти & 1 & $5 \%$ \\
\hline 6 & Все товары & 4 & $21 \%$ \\
\hline
\end{tabular}

Далее респондентам был задан вопрос о причинах, по которым они предпочитают осуществлять покупки через интернет. Ответы на него были сведены в таблицу 2.

В большинстве случаев причиной покупки через интернет является более низкая цена по сравнению с традиционным магазином. Часть респондентов отметили главной причиной возможность 
прочитать отзывы о товаре от других покупателей, посчитав такой подход более целесообразным, чем общение с консультантом в магазине.

Таблицуа 2.

Причины, по которым клиенты выбирают интернет-магазины

\begin{tabular}{|c|c|c|}
\hline $\begin{array}{c}\text { № } \\
\text { п.п. }\end{array}$ & Причина & $\begin{array}{c}\text { Доля } \\
\text { респондентов }\end{array}$ \\
\hline 1 & Дешевле & $53 \%$ \\
\hline 2 & Не нужно общаться с продавцами & $21 \%$ \\
\hline 3 & Возможность прочитать отзывы о товаре & $16 \%$ \\
\hline 4 & Удобнее/наличие доставки & $10 \%$ \\
\hline
\end{tabular}

Интересно отметить, что почти четверть респондентов отказывается от традиционного магазина именно из-за нежелания общаться с продавцами. Вероятно, это связано с излишней навязчивостью консультантов и изменением в укладе современного общества. Изза быстрого перехода к цифровой среде, заметная часть молодежи в возрасте 18-22 лет чувствуют себя более комфортно, когда им не нужно общаться с продавцами вживую $[17,18]$. Им будет удобнее получить информацию об интересующем товаре через СМС (сейчас многие интернет-магазины предлагают консультацию прямо на сайте интернет-магазина).

Далее авторы предлагают рассмотреть описываемые выше модели поведения потребителей, которые порождают феномен паразитирования в торговле. Напомним, что посетитель может:

1. Выбрать товар в интернете, а затем проверить его качества в традиционном магазине (и потом, возможно, приобрести его в интернете).

2. Найти необходимый товар в традиционном магазине, а затем купить его через интернет (на сайте того же магазина или у другого оператора электронной торговли).

Для исследования первой модели поведения респондентам был задан вопрос: “Если Вы нашли подходящий по описанию товар в интернете, купите ли Вы его сразу?”. Ответы респондентов поделились практически поровну: 53\% приобретут его сразу, а 47\% - нет. 
Респондентам, готовым приобрести товар сразу, был задан вопрос, приобретут ли они товар на том сайте, где он был выбран или нет. Ответы на данный вопрос представлены на диаграмме 1, которая показывает, что клиенты не склонны искать аналогичный товар на других сайтах. Только 1 респондент заявил о готовности поиска аналогичного товара на другом сайте, чтобы сэкономить в случае, если на других сайтах данный товар будет предложен по более низкой цене.

Диаграмма 1.

Действия покупателей, готовых приобрести товар через интернет сразу

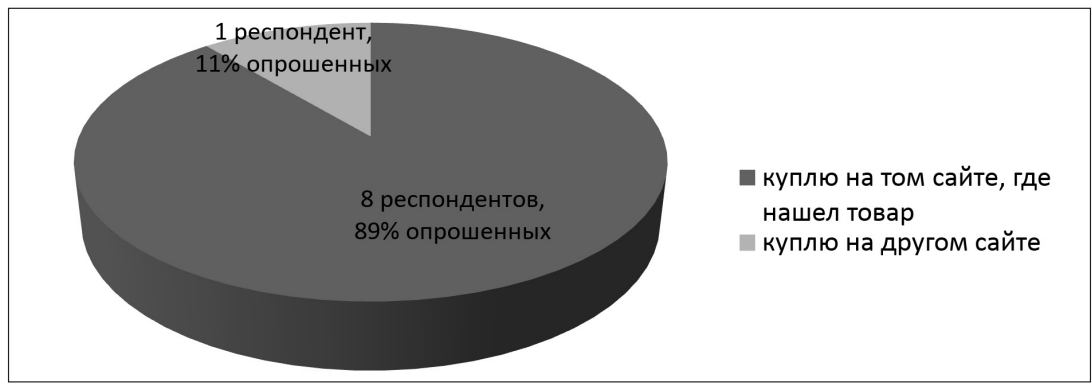

Респондентов, которые не готовы к осуществлению покупки сразу, попросили описать их действия перед совершением покупки. Их ответы были структурированы и отражены в диаграмме 2.

Диаграмма 2.

Действия покупателей, не готовых к совершению покупки сразу

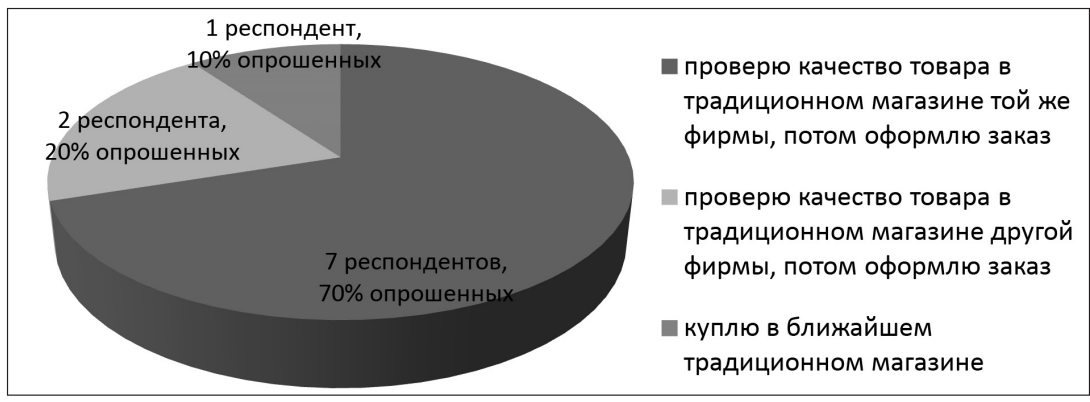

Результат подтверждает существование феномена паразитирования. В 70\% случаев клиенты проверяют качество товара в тради- 
ционном магазине той же фирмы и лишь после этого совершают покупку, что может рассматриваться как внутрифирменное паразитирование. Межфирменное паразитирование встречается значительно реже (20\% респондентов). В данном случае оно возникает из-за желания покупателя сэкономить время на проверке качества товара, поэтому он просто выбирает ближайший магазин, где можно ознакомиться с выбранным товаром.

Далее рассмотрим вторую модель поведения. Для этого респондентам было предложено представить, что они выбрали товар, находясь в традиционном магазине и ответить на вопрос, где они осуществят покупку. Результат представлен в виде диаграммы 3.

Диаграмма 3.

Поведение покупателей после выбора товара в традиционном магазине

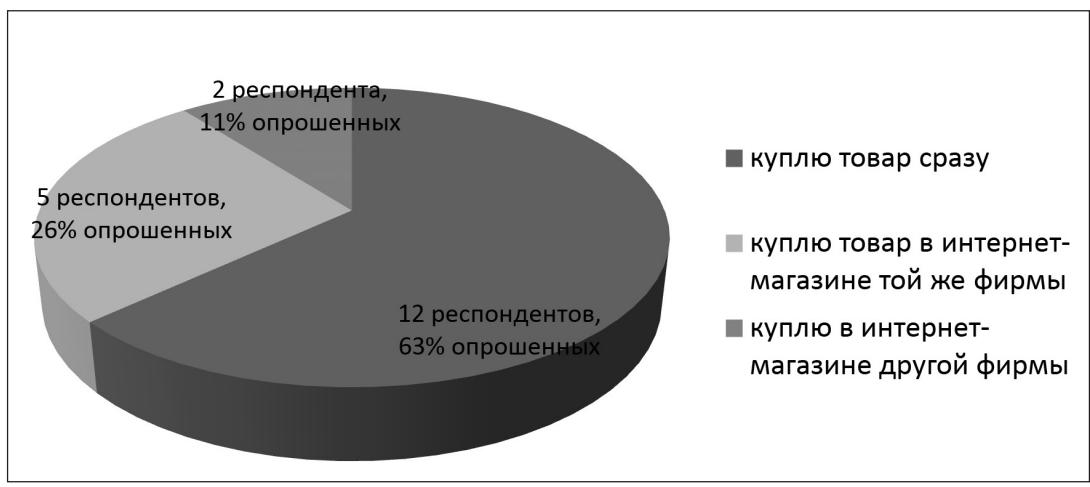

Исходя из ответов, можно сделать вывод, что покупатели, которые приходят в магазин, не выбирая товар предварительно в интернете, готовы приобретать его сразу. Только 37\% респондентов приобретут товар через интернет после посещения традиционного магазина, при этом большинство выберет интернет-магазин той же фирмы. Респонденты, которые приобретут товар в интернет-магазине другой фирмы, вероятно, преследуют цель максимальной экономии средств, поэтому будут готовы потратить больше времени на поиск самого дешевого интернет-магазина. 


\section{Обсуждение}

Проведенный опрос позволяет утверждать, что феномен паразитирования действительно существует. Тем не менее, проявляется он, как мы полагаем, в менее яркой форме по сравнению с тем периодом, когда концепция паразитирования была впервые предложена в научной литературе [8]. Это можно объяснить как трансформацией поведения потребителей, так и формированием у розничных операторов компетенций в области противодействия паразитированию.

Однако если внутрифирменное паразитирование стало проявляться менее заметно, то межфирменное паразитирование попрежнему существует. По этой причине розничным операторам необходимо внедрять инструменты противодействия такому поведению потребителей.

\section{Заключение и выводы}

Выполненное нами исследование позволяет утверждать следующее:

- феномен паразитирования в интернет-коммерции, представляющий стремление потребителей безвозмездно использовать ресурсы традиционных магазинов при ориентации на совершение покупки в интернет-магазине, действительно существует, хотя и не является широко распространенным;

- приобретение товаров онлайн становится для нового поколения потребителей предпочтительным способом совершения покупки не только по причине более низких цен, но и из-за перехода к новой модели потребления, ориентированной на виртуальные продажи без взаимодействия с продавцами-консультантами;

- исключить межфирменное паразитирование затруднительно, тогда как для борьбы с внутрифирменным паразитированием необходимо формировать единый канал взаимодействия с потребителем, в рамках которого интернет-канал и традиционный канал продажи совместно формируют ценность [19];

- современные технологии взаимодействия с потребителем позволяют делать для него персонифицированные предложения, 
которые снижают привлекательность поиска альтернативных вариантов покупки [3, 7]. Это позволит закрепить потребителя в сформированном едином канале продаж.

\section{Список литературы}

1. Бахарев В.В., Митяшин Г.Ю. Тенденции развития ритейла в России // Экономический вектор. 2020. № 3 (22). С. 54-60.

2. Бахарев В.В., Соловьева В.Г. Интернет торговля - инновационная форма развития торговли // «Неделя науки СПбПУ»: материалы научной конференции с международным участием. СПбПУ Петра Великого, Институт промышленного менеджмента, экономики и торговли. 2016. С. 232-235.

3. Быковский Г.В. Управление отношениями с клиентами в российской интернет-коммерции: примеры компаний «Кей» и «Юлмарт» // Интернет-маркетинг. 2017. № 4. С. 312-324.

4. Герасикова Е.Н., Власова А.А. Современные тенденции развития интернет-маркетинга и электронной торговли // Universum: экономика и юриспруденция. 2019. № 1 (58). С. 4-8.

5. Каманина Р.В. Электронная торговля - ключевое направление экономического развития страны // Экономика и управление: проблемы, решения. 2018. Т.1. № 8. С. 14-21.

6. Котляров И.Д. Тенденции эволюции электронной коммерции // Интернет-маркетинг. 2012. № 4. С. 252-258.

7. Котляров И.Д. Услуга или манипулирование: взаимодействие интернет-магазинов с потребителями // Интернет-маркетинг. 2013. № 6. С. 358-364.

8. Котляров И.Д. Феномен паразитирования в интернет-коммерции // Управление продажами. 2015. № 3. С. 198-201.

9. Котляров И.Д. Формы ведения предпринимательской деятельности в виртуальном пространстве: попытка классификации // Экономическая наука современной России. 2011. № 2. С. 89-100.

10. Красюк И.А., Бахарев В.В., Медведева Ю.Ю. Инновационные решения в розничной торговле // Инновационная экономика: перспективы развития и совершенствования. 2017. № 3 (21). С. 32-38. 
11. Красюк И.А. Инновации в торговле как инструмент повышения потребительской лояльности. Наука и инновации в современных условиях: сб. ст. Междунар. науч.-практ. конф. (18 декабря 2016 г., г. Екатеринбург). В 5 ч. 1. Уфа: МЦИИ ОМЕГА САЙНС, 2016. C. $178-182$.

12. Макаров В.В., Колотов Ю.О. Развитие интернет-коммерции // Экономический анализ: теория и практика. 2009. № 26 (155). С. 60-64.

13. Максиянова Т.В. Место и роль интернет-коммерции в системе интрнет-эономики на современном этапе развития информационной (новой) экономики // Вопросы современной науки и практики. Университет им. В.И. Вернадского. 2011. № 3 (34). С. 256-264.

14. Максиянова Т.В. Принципы организации и факторы развития интернет-коммерции // Вопросы современной науки и практики. Университет им. В.И. Вернадского. 2011. № 2 (33). С. 277-281.

15.Митяшин Г.Ю. Анализ феномена паразитирования в интернет-коммерции. В сборнике: Глобальная экономика в XXI веке: роль биотехнологий и цифровых технологий. сборник научных статей по итогам работы пятого круглого стола с международным участием. Высшая школа МВА IntegraL. Москва. 2020. C. 84-86.

16. Johansson T., Kask J. (2017) Configurations of business strategy and marketing channels for e-commerce and traditional retail formats: A Qualitative Comparison Analysis (QCA) in sporting goods retailing. Journal of Retailing and Consumer Services, vol. 34, pp. 326-333.

17. Michalak W., Calder L. (2003) Integration of e-commerce as a retail channel: impact of youth: on e-commerce trends in Canada. Progress in Planning, vol. 60, pp. 111-126.

18. Nisara Tahir M., Prabhakar G. (2017) What factors determine e-satisfaction and consumer spending in e-commerce retailing? Journal of Retailing and Consumer Services, vol. 39, pp. 135-144.

19. Wagner G., Schramm-Klein H., Steinmann S. (2020) Online retailing across e-channels and e-channel touchpoints: Empirical studies of consumer behavior in the multichannel e-commerce environment. Journal of Business Research, vol. 107, pp. 257-270. 


\section{References}

1. Baharev V.V., Mityashin G.Yu. (2020) Tendencii razvitiya ritejla v Rossii [Retail development trends in Russia]. Ekonomicheskiy vector [Economic vector], no 3 (22), pp. 54-60.

2. Baharev V.V., Solov'eva V.G. (2016) Internet torgovlya - innovacionnaya forma razvitiya torgovli [Internet trade - an innovative form of trade development]. «Nedelya nauki SPbPU»: materialy nauchnoy konferentsii s mezhdunarodnym uchastiem. SPbPU Petra Velikogo, Institut promyshlennogo menedzhmenta, ekonomiki i torgovli [SPbPU science Week: materials of a scientific conference with international participation. Peter the Great SPbPU, Institute of industrial management, Economics and trade], pp. 232-235.

3. Bykovskij G.V. (2017) Upravlenie otnosheniyami s klientami v rossijskoj internet-kommercii: primery kompanij «Kej» $\mathrm{i}$ «Yulmart» [Managing customer relationships in the Russian e-Commerce: examples of companies «Кей» and «Юлмарт»]. Internet-marketing, no. 4, pp. 312-324.

4. Gerasikova E.N., Vlasova A.A. (2019) Sovremennye tendencii razvitiya internet-marketinga i elektronnoj torgovli [Modern trends in the development of Internet marketing and e-Commerce]. Universum: ekonomika i yurisprudentsiya [Universum: Economics and law], no 1 (58), pp. 4-8.

5. Kamanina R.V. (2018) Elektronnaya torgovlya-klyuchevoe napravlenie ekonomicheskogo razvitiya strany [E-Commerce - the key direction of the country's economic development]. Ekonomika i upravlenie: problemy, resheniya [Economics and management: problems and solutions], vol. 1, no. 8, pp. 14-21.

6. Kotlyarov I.D. (2012) Tendencii evolyucii elektronnoj kommercii [Trends in the evolution of e-Commerce]. Internet marketing, no. 4, pp. 252-258.

7. Kotlyarov I.D. (20130 Usluga ili manipulirovanie: vzaimodejstvie internet-magazinov s potrebitelyami [Service or manipulation: interaction of online stores with consumers]. Internet marketing, no. 6, pp. 358-364.

8. Kotlyarov I.D. (2015) Fenomen parazitirovaniya v internet-kommercii [Phenomenon of parasitism in e-Commerce]. Upravlenie prodazhami, no. 3, pp. 198-201.

9. Kotlyarov I.D. (2011) Formy vedeniya predprinimatel'skoj deyatel'nosti v virtual'nom prostranstve: popytka klassifikacii [Forms of doing 
business in the virtual space: an attempt to classify]. Ekonomicheskaya nauka sovremennoy Rossii [Economic science of modern Russia], no. 2, pp. 89-100.

10. Krasyuk I.A., Baharev V.V., Medvedeva Yu.Yu. (2017) Innovacionnye resheniya $\mathrm{v}$ roznichnoj torgovle [Innovative solutions in retail]. Innovacionnaya ekonomika: perspektivy razvitiya i sovershenstvovaniya, no 3 (21), pp. 32-38.

11. Krasyuk I.A. (2016) Innovacii v torgovle kak instrument povysheniya potrebitel'skoj loyal'nosti [Innovations in trade as a tool for increasing consumer loyalty]. Nauka i innovacii v sovremennyh usloviyah: sb. st. Mezhdunar. nauch.-prakt. konf. (18 dekabrya 2016 g., g. Ekaterinburg). $V 5 \mathrm{ch} .1$ [Science and innovation in modern conditions: collection of articles. Art. Int. scientific-practical conf. (December 18, 2016, Yekaterinburg)]. Ufa: MCII OMEGA SAJNS, pp. 178-182.

12. Makarov V.V., Kolotov Yu.O. (2009) Razvitie internet-kommercii [Development of e-Commerce]. Ekonomicheskiy analiz: teoriya i praktika [Economic analysis: theory and practice], no. 26 (155, pp. 60-64.

13. Maksiyanova T.V. (20110 Mesto i rol' internet-kommercii v sisteme intrnet-eonomiki na sovremennom etape razvitiya informacionnoj (novoj) ekonomiki [Place and role of Internet Commerce in the Internet economy system at the present stage of development of the information (new) economy]. Voprosy sovremennoj nauki i praktiki. Universitet im. V.I. Vernadskogo, no. 3 (34), pp. 256-264.

14. Maksiyanova T.V. (2011) Principy organizacii i faktory razvitiya internet-kommercii [Principles of organization and factors of development of e-Commerce]. Voprosy sovremennoj nauki i praktiki. Universitet im. V.I. Vernadskogo, no. 2 (33), pp. 277-281.

15. Mityashin G. Yu. (2020) Analiz fenomena parazitirovaniya v internet-kommercii [Analysis of the phenomenon of parasitism in e-Commerce]. Global'naya ekonomika v XXI veke: rol'biotekhnologij i cifrovyh tekhnologij. sbornik nauchnyh statej po itogam raboty pyatogo kruglogo stola s mezhdunarodnym uchastiem [The Global Economy in the 21st Century: The Role of Biotechnology and Digital Technologies. collection of scientific articles on the results of the fifth round table with 
international participation]. Higher School MBA IntegraL, Moscow, pp. 84-86.

16. Johansson T., Kask J. (2017) Configurations of business strategy and marketing channels for e-commerce and traditional retail formats: A Qualitative Comparison Analysis (QCA) in sporting goods retailing. Journal of Retailing and Consumer Services, vol. 34, pp. 326-333.

17. Michalak W., Calder L. (2003) Integration of e-commerce as a retail channel: impact of youth: on e-commerce trends in Canada. Progress in Planning, vol. 60, pp. 111-126.

18. Nisara Tahir M., Prabhakar G. (2017) What factors determine e-satisfaction and consumer spending in e-commerce retailing? Journal of Retailing and Consumer Services, vol. 39, pp. 135-144.

19. Wagner G., Schramm-Klein H., Steinmann S. (2020) Online retailing across e-channels and e-channel touchpoints: Empirical studies of consumer behavior in the multichannel e-commerce environment. Journal of Business Research, vol. 107, pp. 257-270.

\section{ДАННЫЕ ОБ АВТОРАХ}

Митяшин Глеб Юрьевич, бакалавр направления “Торговое дело” Федеральное государственное автономное образовательное учреждение высшего образования «Санкт-Петербургский политехнический университет Петра Великого» ул. Политехническая, 29, г. Санкт-Петербург, 194064, Российская Федерачия gleb.mityashin@yandex.ru

Катрашова Юлия Валентиновна, бакалавр направления “государственное и муниципальное управление" Федеральное государственное автономное образовательное учреждение высшего образования «Санкт-Петербургский политехнический университет Петра Великого» ул. Политехническая, 29, г. Санкт-Петербург, 194064, Российская Федерация ul.katrashova@gmail.com 


\section{DATA ABOUT THE AUTHORS}

Mityashin Gleb Yurievich, Bachelor of "Trade"

Peter the Great St. Petersburg Polytechnic University

29, Politekhnicheskaya str., St. Petersburg, 194064, Russian Federation

gleb.mityashin@yandex.ru

Katrashova Yuliya Valentinovna, Bachelor of "Public administration" Peter the Great St. Petersburg Polytechnic University 29, Politekhnicheskaya str., St. Petersburg, 194064, Russian Federation ul.katrashova@gmail.com 